\title{
A Mata Atlântica cede lugar a outros usos da terra em Santa Catarina, Brasil
}

\author{
Alexandre Siminski ${ }^{1 *}$ \\ Alfredo Celso Fantini ${ }^{2}$ \\ ${ }^{1}$ PPG em Recursos Genéticos Vegetais - UFSC \\ Pesquisador do Núcleo de Pesquisas em Florestas Tropicais \\ Rodovia Admar Gonzaga, 1346, Itacorubi, CEP 88034-900, Florianópolis - SC, Brasil \\ ${ }^{2}$ Departamento de Fitotecnia e PPG em Recursos Genéticos Vegetais - UFSC \\ Pesquisador do Núcleo de Pesquisas em Florestas Tropicais \\ *Autor para correspondência \\ alesiminski@yahoo.com.br
}

Submetido em 14/08/2009

Aceito para publicação em 17/02/2010

\section{Resumo}

Os pedidos de supressão de vegetação nativa disponíveis na Fundação de Meio Ambiente do Estado de Santa Catarina foram avaliados com o objetivo de conhecer o perfil dos solicitantes, as motivações para a solicitação e as características metodológicas do inventário florestal apresentado. Foram levantadas 1.753 solicitações em 11 coordenadorias. Os resultados mostram que $71 \%$ dos pedidos foram de pessoas físicas, onde o uso econômico alternativo do solo foi a principal justificativa. O reflorestamento com espécies exóticas foi a maior demanda (43\%), representando uma área de 22.000 ha. Em 95\% dos processos foi utilizada a amostragem aleatória simples, com unidades amostrais do tipo área fixa, onde $200 \mathrm{~m}^{2}$ foi a dimensão mais frequente. Houve grande diferença nos critérios nos levantamentos realizados no meio rural e no meio urbano e, em $46 \%$ dos inventários, a relação das espécies apresentadas é discordante da flora característica do estádio sucessional em que a vegetação foi classificada. Os resultados indicam a necessidade de um normatização para a amostragem da vegetação e de uma capacitação e formação continuada dos profissionais que o fazem. Revelam ainda a necessidade imediata de uma política de valorização dos remanescentes florestais nativos.

Unitermos: desmatamento, inventário florestal, Mata Atlântica

\section{Abstract}

The Brazilian Atlantic Forest gives way to other land uses in Santa Catarina state. Deforestation permits $(1,753)$ submitted to the state environmental agency (Fatma) in Santa Catarina state, Brazil, were analyzed in order to establish the profile of applicants, the reasons for request, and the methodological characteristics of forest inventory. The results show that $71 \%$ of applications were from individuals, and the economic use of land was the major reason for requisition. Reforestation with exotic species was the greatest demand (43\%), representing 22 thousand hectares. Random sampling was used in $95 \%$ of inventories, and plots with $200 \mathrm{~m}^{2}$ were the most common size used. Inventory criteria were different between rural and urban areas. Around $46 \%$ of inventories had problems in assigning the species presented into successional stages. The results suggest the need of inventory sampling standardization to classify the vegetation and also training and continuing education for professionals. They also show the immediate need of a policy for native forest usage.

Key words: Brazilian Atlantic forest, deforestation, forest inventory 


\section{Introdução}

Santa Catarina foi o estado que mais suprimiu a vegetação nativa no bioma Mata Atlântica desde o ano 2000: cerca de $45.500 \mathrm{ha}$, correspondentes a um aumento de $7 \%$ em relação ao período anterior (Fundação SOS Mata Atlântica e INPE, 2008).

Em Santa Catarina, como em todo o Brasil, a pressão econômica é um dos motivadores da mudança no uso da terra. O baixo valor das terras cobertas com florestas nativas, como consequência das restrições a possibilidade de usos dos seus recursos, tem exacerbado esse fato, e contribui fortemente para a substituição das áreas florestadas por outros usos. A situação não é nova, mas tem recebido especial atenção na última década, ante a crescente conscientização pública sobre as aceleradas taxas de desmatamento. Tampouco é recente a preocupação com esse passivo ambiental. Apesar de quase esquecida até o final dos anos 1980, o Brasil já contava com Lei específica para o setor florestal desde 1965, quando foi promulgada a Lei 4.771, conhecida como Código Florestal Brasileiro (Brasil, 1965).

O Código Florestal restringiu a utilização de florestas primárias e estabeleceu necessidade de reservar áreas para preservação em todos os estabelecimentos agrícolas, nas categorias Área de Reserva Legal (RL) e Área de Preservação Permanente (APP). Outro grande passo na direção da regulamentação foi a Constituição Federal de 1988 (Brasil, 1988), que passou a considerar a Mata Atlântica um patrimônio nacional, numa tentativa segundo Silveira (1998), de conciliar interesses individuais e coletivos, explicitando a função social frente ao direito de propriedade. A Constituição estabeleceu que é do interesse de toda a sociedade o aproveitamento racional e adequado dos recursos naturais disponíveis nos estabelecimentos agrícolas, assim como a preservação do meio ambiente.

Somente em 1993, entretanto, através do Decreto Federal no 750 (Brasil, 1993), foi regulamentada a Constituição Federal em relação aos instrumentos legais específicos para a Mata Atlântica. Nesse decreto, foram definidos os limites para o uso e conservação da Mata Atlântica e atribuída ao Instituto Brasileiro do Meio Ambiente e dos Recursos Naturais Renováveis
(Ibama) e órgãos ambientais estaduais a prerrogativa de regulamentar a exploração da vegetação. Em 2006, foi aprovada a Lei n ${ }^{\circ} 11.428 / 06$, conhecida como "Nova Lei da Mata Atlântica" (Brasil, 2006), que dispõe sobre a utilização e proteção da vegetação nativa desse bioma. Nos mesmos moldes do Decreto Federal, mas hierarquicamente superior, essa nova Lei passou a disciplinar as possibilidades de uso dos recursos florestais da Mata Atlântica, sendo recentemente regulamentada pelo Decreto n ${ }^{\circ}$ 6.660/08 (Brasil, 2008).

Todo esse aparato legal criou um contexto que restringe fortemente o uso direto dos recursos dos ecossistemas naturais da região, particularmente a supressão da vegetação. Desta forma, qualquer intervenção no ecossistema deve ser precedida de autorização prévia das agências ambientais, estando as possibilidades de intervenção condicionadas pelo estágio sucessional da formação florestal.

Nesse cenário, os casos que demandam maior atenção dessas agências são os de supressão da vegetação, já que em grande parte implicam a mudança no uso da terra. Em Santa Catarina, as autorizações para supressão de vegetação nativa são concedidas pela Fundação de Meio Ambiente (Fatma), que avalia o cumprimento dos requisitos legais e técnicos da proposição. Do ponto de vista técnico, o principal requisito é a determinação do estágio de sucessão em que se encontra a vegetação, que deve ser definida por inventário florestal, realizado por profissional habilitado, com base no que é estabelecido pela Resolução $n^{\circ}$ 04/1994 do Conselho Nacional do Meio Ambiente (CONAMA), convalidada pela Resolução n $388 / 2007$ do CONAMA (Santa Catarina, 2002).

Apesar da área proporcionalmente grande desmatada no Estado, poucos estudos têm sido dedicados a compreender o processo de redução de florestas remanescentes. Assim, além dos dados de área, obtidos por análise de imagens de satélite, há pouca informação disponível. Neste trabalho, foram analisados os processos de solicitação de supressão vegetal submetidos à Fatma com o objetivo de conhecer o perfil dos solicitantes, as motivações para a solicitação, assim como as características metodológicas do inventário florestal apresentado. 


\section{Material e Métodos}

As informações utilizadas neste trabalho foram coletadas por meio da análise dos pedidos de supressão da vegetação submetidos à Fundação de Meio Ambiente de Santa Catarina (Fatma), órgão responsável pelos processos de licenciamento ambiental no Estado.

Foram levantados todos os pedidos de supressão de vegetação nativa (descapoeiramento) protocolados entre os anos 1995 e 2007 na Fatma, disponíveis em 11 coordenadorias regionais, abrangendo as regiões dos municípios de Florianópolis, Tubarão, Itajaí, Blumenau, Joinville, Canoinhas, Criciúma, Lages, Joaçaba, Caçador e Chapecó.

Nos processos foram analisados a justificativa, metodologia, resultados e conclusões referentes aos inventários florestais apresentados por profissionais habilitados, sendo este um dos requisitos obrigatórios das solicitações. As informações foram coletadas em planilhas, posteriormente sumarizadas. A análise dos textos pautou-se no método Análise de Conteúdo (Bardin, 1977; Franco, 2005), relacionando-os com o referencial teórico pesquisado e a visão do pesquisador. Os dados dos inventários florestais foram analisados com estatísticas descritivas (Sokal e Rohlf, 1995). Foram reproduzidos trechos literais de argumentação apresentada pelos técnicos nas solicitações de autorização para supressão de vegetação, para exemplificar a pertinência do argumento na elaboração dos processos.

\section{Resultados e Discussão}

Do período de 1995 a 2007 foram avaliados todos os 1.753 pedidos de supressão da vegetação em Santa Catarina. Admitindo que todas as solicitações tenham sido concedidas, a área desmatada legalmente no Estado somaria cerca de 26.000 ha, o que sugere que existe pressão para a mudança da cobertura florestal nativa para outros usos da terra. Essa área seria equivalente a $60 \%$ da área desmatada dectada pela Fundação SOS Mata Atlântica e INPE no período 2000-2005. Esta mesma estimativa considerando o período integral (19952005) não foi possível por diferenças no método de levantamento utilizado (Fundação SOS Mata Atlântica e INPE, 2008).
Perfil dos estabelecimentos e uso da terra após a supressão da vegetação

A maior parte das solicitações de supressão de vegetação nativa foi apresentada por pessoas físicas (71\%). A proporção de solicitações de pessoas físicas foi maior no meio rural $(82 \%)$ do que na área urbana $(59 \%)$.

$\mathrm{Na}$ área rural, a implantação de reflorestamentos homogêneos com espécies exóticas destacou-se como a principal opção de uso da terra após a supressão da vegetação (Tabela 1). O reflorestamento foi responsável por $65 \%$ do número de pedidos de supressão na zona rural, e quase metade do total de pedidos. A área total requerida para conversão em reflorestamentos entre 1995 a 2007 somou 22.000 ha, e representou $85 \%$ da área total dos pedidos de supressão de vegetação no Estado.

Chama também a atenção o perfil dos estabelecimentos rurais para os quais foi solicitada a conversão do uso da terra para reflorestamento e para lavoura/pecuária: o tamanho médio dos estabelecimentos foi 5,4 vezes nos casos de reflorestamento e a área média a ser suprimida foi 6,5 vezes maior para os mesmos casos (Tabela 1).

Além disso, foi possível constatar, em termos cronológicos, uma gradativa mudança no perfil de quem solicita autorização para implantação de reflorestamentos. No início do período analisado havia um maior equilíbrio entre solicitações de pessoas físicas (59\%) e pessoas jurídicas (41\%) e a área média a ser suprimida era de 337 ha. A partir de 2001, o número de solicitações das pessoas físicas aumentou sete vezes, com redução da área média para 104ha. Esses resultados refletem a tendência recente de pequenos agricultores passarem a plantar florestas homogêneas com espécies exóticas, estimulados por programas governamentais ou por sistemas de integração com indústrias do setor.

Segundo dados da Sociedade Brasileira de Silvicultura (SBS, 2008) a área plantada de florestas em Santa Catarina cresceu de 35.9670ha em 2001 para 49.2000ha em 2004, com um aumento médio 45.000ha ano, taxa de incremento que era esperada até 2007. 
TABELA 1: Finalidade de uso da terra e características dos estabelecimentos para os quais foi solicitada autorização para supressão de vegetação nativa em Santa Catarina, avaliada no período de 1995 a 2007.

\begin{tabular}{|c|c|c|c|c|c|}
\hline \multirow{2}{*}{ Zona } & \multirow{2}{*}{ Finalidade } & \multirow{2}{*}{$\begin{array}{l}\text { Número de } \\
\text { processos }\end{array}$} & \multicolumn{3}{|c|}{$\begin{array}{l}\text { Área média dos } \\
\text { estabelecimentos (ha) }\end{array}$} \\
\hline & & & Total & $\underset{\text { suprimir }}{\mathrm{A}}$ & $\%$ \\
\hline \multirow{3}{*}{ Rural } & Reflorestamento & 763 & 143,8 & 28,9 & 20,1 \\
\hline & $\begin{array}{l}\text { Lavoura / } \\
\text { pecuária }\end{array}$ & 345 & 26,4 & 4,4 & 16,8 \\
\hline & Outros & 76 & 11,3 & 2,4 & 21,5 \\
\hline \multicolumn{2}{|c|}{ Total / Médias } & 1.184 & 92,9 & 18,7 & 20,1 \\
\hline \multirow{3}{*}{ Urbana } & Construção civil & 389 & 5,1 & 1,5 & 30,2 \\
\hline & Loteamento & 160 & 10,7 & 3,6 & 33,1 \\
\hline & Outros & 20 & 16,7 & 8,2 & 49,2 \\
\hline \multicolumn{2}{|c|}{ Total / Médias } & 569 & 7,6 & 2,4 & 31,5 \\
\hline
\end{tabular}

Este período de crescimento coincidiu com a criação em 2000 do Programa Nacional de Florestas (PNF), vinculado ao Ministério do Meio Ambiente (MMA). Entre as metas até 2007, estavam a expansão da base florestal plantada, prevendo 1.200.000ha plantados em programas empresariais e 800.000 ha plantados em pequenas médias propriedades. Como forma de incentivo, o PNF promoveu em 2002 o lançamento do PROPFLORA, para apoiar pequenos e médios produtores rurais a implantarem e manterem suas florestas comerciais, e o Programa Nacional de Agricultura Familiar para as atividades florestais (PRONAF Florestal) (Ministério do Meio Ambiente, 2000; Mendes, 2005).

Ainda segundo as projeções feitas neste período, a forte demanda por madeira implicaria no aumento da área plantada. Até o ano 2010, a projeção era de que a área atual crescesse $4 \%$ a.a., e $1 \%$ a.a. posteriormente (Mendes, 2005). Pela falta de grandes áreas para o plantio no sul do Brasil, somada as restrições do uso do solo por questões ambientais (áreas de grande declividade, beira de rios, reserva legal e outros), esperava-se que a expansão das áreas plantadas ocorresse principalmente em pequenas e médias propriedades rurais (Pires e Dalmora, 2004), o que está de acordo com a mudança no perfil dos estabelecimentos onde se solicitou supressão da vegetação.

O PNF, formulada pelo MMA, seguiu a mesma linha em Santa Catarina no que tange ao apoio financeiro e técnico aos pequenos e médios produtores rurais, através do Programa Florestal Catarinense (1998-2002). O Programa Florestal Catarinense, em termos gerais, atendia a um conjunto múltiplo de objetivos, dentre os quais, ressalta-se o fornecimento de matéria-prima para o setor industrial de papel e celulose e da indústria moveleira; o predomínio de incentivos para as espécies de pinus e eucalipto, que garante qualidade de produção e expansão da cultura nas diversas regiões do estado; e, incentivos, por meio de crédito, para agricultores familiares (Secretaria do Desenvolvimento Rural e da Agricultura, 2000).

Estas perspectivas estavam baseadas em um cenário de crescimento econômico mundial associado a uma expansão no consumo de madeira, papel e celulose muito presente e amplamente divulgado pelo setor florestal catarinense e brasileiro. Apesar de não existirem ainda dados oficiais, o prognóstico é de redução no aumento da área plantada e nos valores pagos pelos recursos florestais em geral, principalmente aos produtos destinados à exportação (ABIMICI, 2009), onde estão presentes especialmente as espécies de Pinus spp.

Os dados obtidos nesta pesquisa deixam margem para especulação sobre a origem da área plantada. Considerando a taxa média de aumento de 45.000ha por ano somente no período de 2001 a 2007 (sete anos), temse uma área plantada de $315.000 \mathrm{ha}$. Se em todo o período aqui analisado, de 1995 a 2007, foi solicitada a supressão de um total de 22.000ha para reflorestamento, e supondo que todos os pedidos tivessem sido aceitos, haveria ainda 293.000ha que foram convertidos de outros usos da terra. É possível que parte dessa área é resultado da conversão de campos nativos e naturalizados para plantios florestais e/ou que outra parcela significativa dessa área tenha sido desmatada sem autorização da Fatma.

Apesar de não existirem dados, é fato que parcelas dos campos naturais do Estado estão sendo convertidas em plantios florestais homogêneos. Como nestas áreas não há a supressão de material lenhoso, não haveria a 
necessidade de solicitar formalmente a supressão da vegetação, mesmo que estas formações também façam parte do Bioma Mata Atlântica (Lei $\mathrm{n}^{\mathrm{o}}$ 11.428/06). Atualmente, está em discussão no CONAMA uma regulamentação específica para definir os estágios de regeneração da vegetação nativa em áreas de campos de altitude.

Esta grande diferença também não conseguiu ser capturada nos levantamentos da Fundação Mata Atlântica e INPE, pois a inclusão de fragmentos menores nos levantamentos de 2000 e 2005 (10ha e 5ha respectivamente), em relação a 1995 (25ha), possivelmente contribuiu muito mais para o aumento da áreas de remanescentes no estado (de 1.666.241ha em 1995 para 2.189.883ha em 2005) do que o que foi eventualmente suprimido.

\section{Motivação dos solicitantes}

Em relação à justificativa apresentada nos processos para a supressão de vegetação, destaca-se a intenção do uso econômico do solo. Através da análise das justificativas apresentadas nos pedidos para supressão de vegetação, evidencia-se a concepção que muitos proprietários das áreas e profissionais que realizam os inventários têm de que as formações florestais secundárias possuem baixa importância econômica e também ecológica, como ilustram os trechos reproduzidos a seguir:

"Salientamos que nosso departamento de engenharia já procedeu à visitação "in loco" a todos os pontos e seu parecer é de que se justifica o corte em função do aproveitamento agrícola da área preferencial para o cultivo e de que na vegetação existente não se encontra sequer resquício de Mata Atlântica. Trata-se de mata remanescente de cortes antigos, transformando-se em capoeira".

"O objetivo da supressão de vegetação pleiteada pelo presente processo é a transformação de uma vegetação heterogenia de pouca expressão econômica ou ambiental em uma floresta homogênea de elevada expressão econômica".

"O objetivo é a formação de uma floresta de grande valor econômico. Sabedores que o déficit de madeira no mundo é realmente preocupante e cada hectare de floresta plantada corresponde a 30ha de mata nativa, e que cada hectare de reflorestamento consome dez toneladas de carbono da atmosfera (protocolo de Kyoto). Também conhecedores de que o eucalipto não prejudica o solo e muito menos consome água em excesso como diz a lenda, pois consome a mesma quantidade da mata nativa".

"A retirada da vegetação é indispensável para segurar um bom grau de utilização da propriedade, bem como romper as barreiras agrícolas, para o desenvolvimento da agricultura na propriedade".

“A área em questão possui aptidão para reflorestamento, constituindo de uma vegetação constituída de capoeira suja, sem representatividade. A prática do reflorestamento tornará a área de baixa produtividade em propriedade produtiva, o que vem a implementar a política florestal brasileira".

Siminski e Fantini (2007) já apontaram que as restrições ao uso dos ecossistemas florestais e seus recursos são uma das causas dessa percepção. Como afirmaram os autores, as áreas de formações florestais deixaram de ser um elemento integrante do sistema produtivo nos estabelecimentos agrícolas, seja pela exploração direta dos recursos, seja através da agricultura de pousio, essa praticamente inviável sob o atual aparato legal. Não é surpresa, portanto, que a conversão da floresta para outros usos econômicos da terra seja buscada.

No caso da conversão para florestas homogêneas o preço da madeira constitui um forte estímulo. Entre os anos de 1997 e 2005, o preço de madeira de Eucalyptus spp. apresentou um crescimento acumulado de 329\%, equivalente a crescimento médio anual da ordem de $20 \%$. Já o preço da madeira de Pinus spp., no mesmo período, teve um aumento de $700 \%$ para celulose e $500 \%$ para serraria, com a fase de maior incremento começando entre os anos de 2000 e 2001 (Mendes, 2005).

A ampliação dos perímetros urbanos na maior parte dos municípios também tem promovido a substituição de áreas anteriormente destinadas à agricultura por áreas de uso comercial e imobiliário. Nesse caso, além do aumento do valor da terra, a maior possibilidade de supressão da vegetação potencializa a sua substituição. 


\section{Características metodológicas dos in- ventários florestais}

De maneira geral, as características técnicas dos projetos para supressão da vegetação são de baixa qualidade. A falta de preparo de muitos profissionais na elaboração do projeto fica evidente nas deficiências apresentadas na realização do inventário da vegetação e na apresentação dos seus resultados. Este problema é agravado pela ausência de regras claras para a realização dos inventários, o que deixa margem para diferentes interpretações e mesmo tendenciosidade dos resultados (Siminski e Fantini, 2004).

Como características dos inventários apresentados, em $95 \%$ dos processos submetidos no período estudado foi utilizada a amostragem aleatória simples, com unidades amostrais do tipo área fixa (parcela), com dimensões entre 20 e $5.000 \mathrm{~m}^{2}$, sendo $200 \mathrm{~m}^{2}$ a dimensão mais frequente.

É interessante ressaltar que apesar da área média de vegetação a ser suprimida nas propriedades no meio rural ser 7,8 vezes maior que no meio urbano, o número médio de unidades amostrais é quase igual, enquanto que o tamanho médio das parcelas é 1,4 vezes menor, o que acaba refletindo um percentual amostrado dez vezes menor na área rural (Tabela 2). Também é possível identificar a grande diferença no critério de amostragem adotado nos processos em área rural, onde o percentual da área amostrado foi 4,7 e o diâmetro de inclusão 1,4 vezes menor nos processos para fins de reflorestamento em relação à lavoura/pecuária.

Ficou evidente a grande diferença no critério de inclusão de indivíduos nos levantamentos realizados no meio rural e no meio urbano. Essa característica pode estar associada ao grau de permissão de intervenção; enquanto que no meio rural somente é permitida a supressão de vegetação em estágio inicial de regeneração, em áreas urbanas é possível fazer a supressão em estágio médio e avançado.

Os inventários florestais para solicitação de supressão da vegetação, apresentados em sua grande maioria elaborados por Engenheiros Agrônomos, Engenheiros Florestais ou Biólogos, apresentam deficiências metodológicas que vão desde a dificuldade de definição do objeto do levantamento, em sua maioria formações florestais secundárias (capoeiras), até a falta ou imprecisão da descrição clara dos métodos utilizados no levantamento.

Alguns exemplos extraídos de inventários apresentados ilustram este ponto: "Primária em estágio inicial, degradada e sem valor comercial". "A foto mostra outro ângulo do tipo de vegetação terciária, sem valor comercial". "Floresta secundária primitiva em estágio inicial de regeneração". "Utilizou-se a amostragem inteiramente aleatória onde as parcelas foram alocadas conforme caminhamento". "Utilizamos apenas uma amostra na área inventariada ( $6,2 \mathrm{ha}$ ), pois trata-se de uma floresta com poucos remanescentes e com tamanhos bem definidos".

TABELA 2: Características da amostragem utilizadas nos inventários florestais para solicitação de supressão de vegetação nativa junto a Fundação do Meio Ambiente (Fatma), avaliado no período de 1995 a 2007.

\begin{tabular}{|c|c|c|c|c|c|c|}
\hline \multirow[t]{2}{*}{ Zona } & \multirow[t]{2}{*}{ Finalidade } & $\begin{array}{l}\text { Área a } \\
\text { suprimir }\end{array}$ & $\begin{array}{l}\text { Unidades } \\
\text { amostrais }\end{array}$ & $\begin{array}{l}\text { Área } \\
\text { UA }\end{array}$ & $\begin{array}{l}\text { Percentual } \\
\text { amostrado }\end{array}$ & $\begin{array}{l}\text { Diâmetro } \\
\text { de inclusão }\end{array}$ \\
\hline & & (ha) & (UA) & $\left(\mathrm{m}^{2}\right)$ & $(\%)$ & $(\mathrm{cm})$ \\
\hline \multirow{3}{*}{ Rural } & Reflorestamento & 28,9 & 5,3 & 241,8 & 0,4 & 2,7 \\
\hline & Lavoura / pecuária & 4,4 & 3,7 & 220,8 & 1,9 & 3,7 \\
\hline & Outros & 2,4 & 2,1 & 231,1 & 2,0 & 3,1 \\
\hline & Total / Médias & 18,7 & 4,7 & 240,8 & 0,6 & 2,9 \\
\hline \multirow{4}{*}{ Urbana } & Construção civil & 1,5 & 3,9 & 298,1 & 7,8 & 3,6 \\
\hline & Loteamento & 3,6 & 5,8 & 436,3 & 7,0 & 4,2 \\
\hline & Outros & 8,2 & 4,2 & 352,1 & 1,8 & 4,4 \\
\hline & Total / Médias & 2,4 & 4,5 & 339,7 & 6,4 & 3,7 \\
\hline
\end{tabular}


Na grande maioria dos casos (85\%), não é apresentada qualquer estatística que permita avaliar o grau de variação dos dados, como o desvio padrão, variância, erro padrão da média, intervalo de confiança ou outro. Em proporção ainda maior $(90 \%)$ dos processos não é calculada uma intensidade de amostragem ou suficiência amostral, como sugerido no procedimento do inventário florestal (Péllico Netto e Brena, 1997), e nos poucos casos que é apresentado o cálculo foi efetuado de forma incorreta ou o resultado não foi levado em consideração.

Na Tabela 3 é possível visualizar os resultados médios obtidos pelos inventários florestais apresentados para a caracterização do estágio de regeneração de acordo com a resolução CONAMA no 04/1994. Em termos metodológicos é possível observar a diferença entre o diâmetro mínimo de inclusão dos indivíduos quando o resultado final foi a definição do estágio inicial em relação aos outros estágios.

Os resultados dos parâmetros calculados para o estágio inicial evidenciam valores muito próximos aos limites de definição deste estágio de acordo com a Resolução (DAP médio $8 \mathrm{~cm}$, altura média $4 \mathrm{~m}$ e área basal $8 \mathrm{~m}^{2} /$ ha, CONAMA n $\left.{ }^{\circ} 04 / 1994\right)$. Esta tendência também é verificada quando se analisa o valor da moda destes parâmetros, ficando em $8 \mathrm{~cm}, 4 \mathrm{~m}$ e $7,5 \mathrm{~m}^{2} / \mathrm{ha}$, respectivamente.

A análise dos processos revelou a existência de elevado grau de dificuldade por parte dos profissionais em apresentar os dados do inventário de forma correta. A variável com maior problema é a Área Basal, que em $39 \%$ dos casos é apresentada como um valor médio dos indivíduos da parcela e não o somatório deles, como seria correto. Muitas vezes, essa variável, apesar de necessária para a determinação do estágio de sucessão da vegetação, nem mesmo foi apresentada.

Há também um grande número de casos em que o inventário teve como objeto principal a definição do volume de madeira a ser extraído, e não a definição do estágio de regeneração que o remanescente se encontra. Apesar de a estimativa poder ser relevante para o proprietário da área, não tem significado para o propósito do processo submetido à Fatma.

A correta determinação das espécies botânicas é outra dificuldade evidente nos processos. O problema inclui a grafia incorreta e até mesmo a apresentação de nomes de plantas que não existem. Na maior parte dos casos, porém, observou-se a apresentação de um grande número de plantas não identificadas ou identificadas incorretamente a partir do nome vernacular, como revelam os exemplos seguintes: cafezeiro-do-mato (Coffea arabica), leiteito (Euphorbia pulcherrima), palmito (Euterpe oleraceae), licurana (Louroupita guianensis), goiaba (Feijoa sellowiana), carne-de-vaca (Linocleura mandiocanna). Também há limitações na definição da tipologia florestal onde foi feito o levantamento, como por exemplo, a classificação da vegetação como Floresta Ombrófila Mista em municípios inteiramente localizados na área de ocorrência da Floresta Estacional Decidual.

Há que se reconhecer que a grande diversidade de espécies dos ecossistemas da Mata Atlântica impõe certo grau de dificuldade ao trabalho dos técnicos, como também sugere Jaster (2002). Mas esse fato, antes de ser um problema, caracteriza uma situação que valoriza

TABELA 3: Resultados dos parâmetros de caracterização dos estádios sucessionais da Mata Atlântica de acordo com inventários florestais apresentados à Fundação de Meio Ambiente (Fatma), avaliados no período de 1995 a 2007. Valores entre parênteses representam o desvio padrão.

\begin{tabular}{ccccccc}
$\begin{array}{c}\text { Estágio de } \\
\text { Regeneração }\end{array}$ & $\begin{array}{c}\text { Número } \\
\text { processos }\end{array}$ & $\begin{array}{c}\text { DAP mínimo } \\
\text { a medir }(\mathrm{cm})\end{array}$ & $\begin{array}{c}\text { DAP } \\
\text { médio }(\mathrm{cm})\end{array}$ & $\begin{array}{c}\text { Altura Total } \\
\text { Média }(\mathrm{m})\end{array}$ & $\begin{array}{c}\text { Área Basal } \\
\left(\mathrm{m}^{2} / \mathrm{ha}\right)\end{array}$ & $\begin{array}{c}\text { Volume aparente } \\
\left(\mathrm{mst}^{1}\right)\end{array}$ \\
\hline Inicial & 1.016 & $2,9(1,5)$ & $6,9(2,1)$ & $3,75(0,9)$ & $7,5(3,0)$ & $44,3(33,1)$ \\
Médio & 464 & $4,1(2,6)$ & $11,8(4,7)$ & $6,61(2,0)$ & $14,3(9,1)$ & $112,9(79,3)$ \\
Avançado & 78 & $4,4(2,1)$ & $15,8(6,8)$ & $8,25(1,8)$ & $25,6(13,7)$ & $216,9(230,0)$ \\
\hline
\end{tabular}

1 - metro estéreo. 
o trabalho especializado dos técnicos. Ele evidencia, também, a necessidade da capacitação continuada desses profissionais, particularmente para a realização de inventários florísticos e florestais.

Mas o sistema legal também tem parte da responsabilidade no problema. Uma das deficiências existentes é a falta de normatização para a amostragem da vegetação. Por exemplo, a falta de regras para inclusão de indivíduos na amostra, torna ineficazes os valores-limite de diâmetro e altura médios das parcelas e impossibilita sua utilização para a diferenciação dos estádios de sucessão da vegetação (Siminski e Fantini, 2004).

Os dados levantados neste trabalho revelam que em pelo menos 46\% (806) dos inventários a relação das espécies apresentadas é discordante da flora característica do estádio sucessional em que a vegetação foi classificada. Apesar desta constatação, na grande maioria dos casos somente os parâmetros estruturais da vegetação (DAP médio, Altura Total média e Área Basal) foram levados em consideração para a concessão da autorização de desmate. Como sugerido no Capítulo II, as espécies dominantes de uma formação florestal são determinantes para definir em que estágio sucessional essa se encontra.

Os resultados deste trabalho revelam um diagnóstico preocupante sobre a questão dos remanescentes de florestas nativas no estado de Santa Catarina, especialmente das formações florestais secundárias. De um lado, há um desconhecimento dos ecossistemas florestais por parte dos profissionais que trabalham diretamente com a questão. Do outro lado, os proprietários destas áreas de remanescentes que declaram motivação, especialmente econômica, em suprimi-los.

Esta situação revela a fragilidade em termos de conservação efetiva que esses remanescentes estão submetidos. Exemplo dessa fragilidade é a substituição das áreas de florestas nativas por outras formas de uso da terra. Nesse caso, a opção basicamente pelos reflorestamentos com espécies exóticas é apenas reflexo do contexto florestal atual, onde os rendimentos econômicos e políticas florestais estimulam esta conversão.
Outro resultado apresentado diz respeito à deficiência técnica de muitos profissionais que apresentam projetos de supressão junto a Fundação de Meio Ambiente, independente da formação acadêmica. Neste sentido, é importante que principalmente as entidades de classe que representam estes profissionais invistam em capacitação e formação continuada, pensando no constante aprimoramento da qualidade dos trabalhos elaborados pelos profissionais.

A falta de conhecimento dos técnicos sobre a flora e a vegetação da Mata Atlântica no Estado é um fator que fortalece a intenção de mudança de uso das terras ainda florestadas, pois reflete também o desconhecimento das oportunidades de aproveitamento do potencial dos remanescentes florestais como promotores de produtos $\mathrm{e}$ serviços, e contribui para o fortalecimento da percepção de que florestas nativas, principalmente secundárias, não têm valor econômico.

O contexto apresentado demonstra a necessidade imediata de uma política de valorização dos remanescentes florestais nativos. Essa valorização poderia se dar pelo pagamento por serviços ambientais produzidos pelos ecossistemas, mas poderia, principalmente, se dar pelo incentivo ao manejo econômico das formações secundárias, a exemplo do que propõem Fantini e Siminski (2007). A outra abordagem, da fiscalização e punição, tem se mostrado pouco efetiva.

\section{Agradecimentos}

Os autores agradecem à Fundação de Meio Ambiente (Fatma) pela autorização de pesquisa aos processos (Ofício DICA/GELAR n ${ }^{\circ} 749$ ), ao CNPq pelo apoio financeiro e bolsa de Doutorado (141730/2006-4) e Doutorado Sanduíche no Exterior (201423/2007-3) e a Fapesc pelo apoio financeiro (Edital $n^{0} 01 / 2006$ ).

\section{Referências}

ABIMICI - Associação Brasileira da Indústria de Madeira Processada Mecanicamente. 2009. Crise afeta setor florestal brasileiro e pode gerar desemprego. Disponível em $<$ http:www. abimici.com.br/noticias>. Acesso em 15 de fevereiro de 2009.

Bardin, L. 1977. Análise de conteúdo. Edições 70, São Paulo, Brasil, 117pp. 
Brasil. 1965. Lei $\mathrm{n}^{\circ}$. 4.771, de 15 de setembro de 1965: Institui o Novo Código Florestal. In: Santa Catarina (Ed.). Coletânea da legislação ambiental aplicável no Estado de Santa Catarina. FATMA, Florianópolis, Brasil, p.429-433.

Brasil. 1988. Constituição da República Federativa do Brasil: Promulgada em 5 de outubro de 1988. Disponível em <http://www. planalto.gov.br/ccivil_03/Constituicao/Constituiçao.htm>. Acesso em 9 de setembro de 2007 .

Brasil. 1993. Decreto ${ }^{\circ}$. 750, de 10 de fevereiro de 1993: Dispõe sobre o corte, a exploração e a supressão de Vegetação Primária ou nos estágios avançados e médio de regeneração da Mata Atlântica. In: Santa Catarina (Ed.). Coletânea da legislação ambiental aplicável no estado de Santa Catarina. FATMA, Florianópolis, Brasil, p.433434.

Brasil. 2006. Lei n ${ }^{\circ} 1.428$ de 22 de dezembro de 2006: Dispõe sobre a utilização e proteção da vegetação nativa do Bioma Mata Atlântica e dá outras providências. Disponível em $<$ http://www. planalto.gov.br/ccivil/_Ato2004-2006/2006/Lei/L11428.htm> Acesso em 18 de fevereiro de 2008.

Brasil. 2008. Decreto $\mathrm{N}^{\circ}$ 6.660, de 21 de novembro de 2008: Regulamenta dispositivos da Lei no 11.428, de 22 de dezembro de 2006, que dispõe sobre a utilização e proteção da vegetação nativa do Bioma Mata Atlântica. Disponível em <http://www.planalto. gov.br/ccivil/Decreto/D6660.htm>. Acesso em 20 de fevereiro de 2009.

Fantini, A. C.; Siminski, A. 2007. De agricultor à agricultor silvicultor: Um novo paradigma para a conservação e uso de recursos florestais no sul do Brasil. Agropecuária Catarinense, 20 $16-18$

Franco, M. L. P. B. 2005. Análise do conteúdo. $2^{\mathrm{a}}$ ed. Liber Livros, Brasília, Brasil, 79pp.

Fundação SOS Mata Atlântica; Instituto Nacional de Pesquisas Espaciais. 2008. Atlas dos remanescentes Florestais da Mata Atlântica Período 2000-2005. Fundação SOS Mata Atlântica; Instituto Nacional de Pesquisas Espaciais, São Paulo, Brasil, $157 \mathrm{pp}$.

Jaster, C. B. 2002. A estrutura como indicadora do nível de desenvolvimento sucessional de comunidades arbóreas da restinga - Uma proposta metodológica. Tese de Doutorado, Universidade Federal do Paraná, Brasil, 197pp.
Mendes, J. B. 2005. Estratégias e mecanismos financeiros para florestas plantadas. Organização das Nações Unidas para Agricultura e Alimentação - FAO, Roma, Itália, 75pp.

Ministério do Meio Ambiente. 2000. Programa Nacional de Florestas - PNF. MMA/SBF/DFLOR, Brasília, Brasil, 52pp.

Péllico Netto, S.; Brena, D. A. 1997. Inventário Florestal. Editorado pelos autores, Curitiba, Brasil, 316pp.

Pires, P. J. da F.; Dalmora, E. 2004. O desenvolvimento florestal no contexto da agricultura familiar catarinense: Limites, contradições e potencialidades para o desenvolvimento rural. Caminhos, 1 (2): 111-136.

Santa Catarina. 2002. Coletânea da legislação ambiental aplicável no estado de Santa Catarina. FATMA, Florianópolis, Brasil, $520 \mathrm{pp}$.

Secretaria de Estado do Desenvolvimento Rural e da Agricultura. 2000. Programa florestal catarinense - Reflorestamento: A nova face agrícola de Santa Catarina. Secretaria de Estado do Desenvolvimento Rural e da Agricultura, Florianópolis, Brasil, 40pp.

Silveira, D. S. D. 1998. A propriedade agrária e suas funções sociais. In: Silveira, D. S. D. \& Xavier, F. S. (Orgs). O Direito Agrário em debate. Livraria do Advogado, Porto Alegre, Brasil, 333pp.

Siminski, A.; Fantini, A. C. 2004. Classificação da Mata Atlântica do litoral catarinense em estádios sucessionais: Ajustando a lei ao ecossistema. Floresta e Ambiente, 11 (2): 20-25.

Siminski, A.; Fantini, A. C. 2007. Roça-de-toco: Uso de recursos florestais e dinâmica da paisagem rural no litoral de Santa Catarina. Ciência Rural, 37: 01-10.

SBS - Sociedade Brasileira de Silvicultura. 2008. Estatísticas. Disponível em <http://www.sbs.org.br/estatisticas.htm>. Acesso em 15 de julho de 2008.

Sokal, R. R.; Rohlf, F. J. 1995. Biometry: The principles and practice of statistics in biological research. $3^{\text {rd }}$ ed. W. H. Freeman and Co., New York, USA, 887pp. 